\title{
Analyzing the Effect of International Standards Details of Reinforced Concrete Buildings on Ductility and Energy Absorption of Structure (A Case Study of Nakhjavan Palace Project)
}

\author{
Nouri, H. ${ }^{1}$, Khorrami rouz, M. ${ }^{2}$, Taghavi, M. ${ }^{3}$, Molaei Shakib, A. R. ${ }^{4}$ \& Sarabi Mianaji, B. ${ }^{5}$ \\ ${ }^{1}$ Design project management, M.Sc. in construction management, AmirKabir University of Technology, Tehran, \\ Iran \\ ${ }^{2} \mathrm{PhD}$ in architecture engineering, University of Tehran \\ ${ }^{3}$ Construction project management, M. Sc. in hydraulic structures, Islamic Azad University, International branch \\ of Kish, Iran \\ ${ }^{4}$ Senior supervisor of Skeleton Construction, B. S. in Civil engineering, Islamic Azad University Central Tehran \\ branch, Tehran, Iran \\ ${ }^{5}$ Senior project designer, M. Sc. in civil engineering-structure, Iran University of Science and Technology, \\ Tehran, Iran \\ Correspondence: David Wolf II, Design project management, M. A in construction management, Amir Kabir \\ University, Tehran, ON., 1943884631, Iran. E-mail: info@hmdnr.com
}

Received: April 25, 2016

doi:10.5539/mas.v10n10p165
Accepted: May 25, 2016

Online Published: July 27, 2016

URL: http://dx.doi.org/10.5539/mas.v10n10p165

\begin{abstract}
As studies have been conducted on structures exposed to earthquake or other similar destructive events revealed, implementation problems during construction have led to slight, serious and irrevocable damage. Meanwhile, with respect to various sensitive and subtle details, implementing concrete structures have not been excluded from this principle or are involved with these problem's consequences. The present study investigated the relation between ductility and energy absorption, especially when the imposed lateral load is alternative. Also, the issue of energy-taking and input energy dissipation in a structure implemented according to international standards details of reinforced was studied. Furthermore, by implementing damage index model based on hysteric energy theory, three index levels including elemental, stratified and general structure damage were presented and the importance of precisely implementing regulation details were interpreted. Moreover, ductility and energy absorption level in tall structures' load revisiting systems as well as structures' non-linear behavior causes were explained. Since this case study focused on bending frame system and shear wall and analyzed total deformation of structures constituting shear wall and rigid frame. The research findings can be useful to determine the effect of implementing international standards details of reinforced concrete buildings on ductility and energy absorption of structure.
\end{abstract}

Keywords: international standards, structure implementation, reinforced concrete, ductility, energy absorption

\section{Introduction}

Mistakes and defects occurred during implementing projects may cause some damages such as fracture, empty additional spaces, or contaminated concrete, which all lead to serious problems. Such mistakes and defects can be considered as the result of efficiency, compression degree, processing system, contaminated hydraulic mixture, contaminated aggregates, and wrong use of additives individually or in group. All these influence ductility and energy absorption level of structure. During implementing stages, common implementing errors can be classified into frame working, reinforcing, concreting, framework removing, executive regulations and technical principles, quality control (ACI, 2014).

Investigating causes of face defects or serious damages of structures provide researchers and project executives with a wide and comprehensive view and makes it possible to present proper and rational technical strategies to solve problems and prevent them as well as making reasonable deductions (ASCE/SEI 7-10, 2010).

Significant growth of earthquake engineering, due to the development of engineering knowledge about structures 
behavior and earthquakes, has led to main changes in various regulations. Given to previous earthquakes experiences and previously reported studies on buildings behavior during earthquake, due to using previous design regulations, many studies have attempted to recognize and improve seismic behavior of structures. For instance, we can refer to FEMA and ATC centers. As instances of these centers' results, it can be also referred to some resources about seismic vulnerability of structures such as FEMA273, FEMA274, FEM356, FEMA357, and ATC 40. Executive regulations of these studies as the basic principles of functional subjects have been used in international regulations. As the most recent efforts in this regard, ASCE41 standard has been recently published with the help of the mentioned research centers and ASCE. This standard has been proposed as a reference in earthquake engineering based on proper and valid performance and alternative for previous related studies.

Given to damages and losses due to earthquake in earthquake-susceptible countries, the necessity of designing and implementing earthquake-resistant structure is inevitable. Also, using standard materials as well as properly observing regulations' details guarantee total strength of buildings against earthquake-caused forces. The absorbability and energy loss in non-linear behaviors under reciprocating loads of earthquake is interpreted as ductility. Ductility or energy dissipation capability is a very important characteristic required by structures that are subjected under seismic force. Nowadays, using computer models and neural networks can help determine the magnitude of promotable earthquakes forces imposed to a structure (Mahmoudi et al., 2016). Each earthquake-resistance structure should be generally ductile. The components of each structure should be also ductile. Therefore, given to the type of structure designed for earthquake-susceptible regions, the materials should be selected and combined such that they can supply ductility. Regarding reinforced concrete structures, the main materials include concrete, rebar and the precise way of implementing. Accordingly, in the present study, the executive criteria and regulations supplying ductility in materials, beams, columns, column connections, and shear walls for a residential building with concrete skeleton have been analyzed.

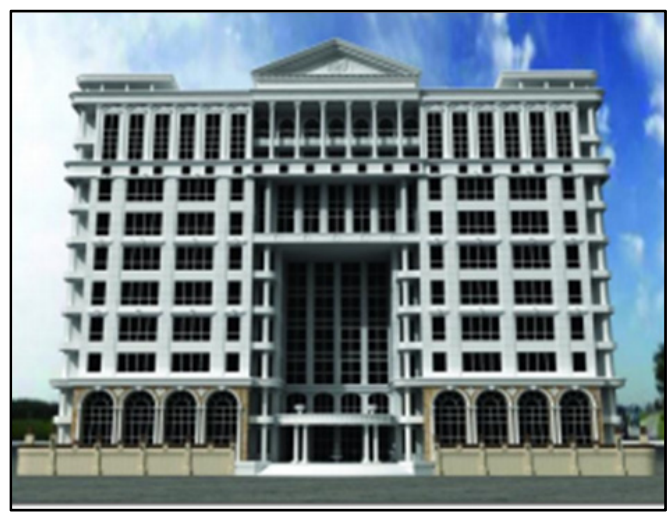

Figure 1. The schematic of Nakhjavan Palace residential building

This work is a case study of Nakhjavan Palace residential building in Tehran located in Niavaran. This building is constructing in an area about $4800 \mathrm{~mm} 2$ with total foundation of $23250 \mathrm{~mm}^{2}$. Its skeleton has been considered 16 stories made of concrete. To supply the strength of the structure against lateral forces, special bending frame system with special shear walls have neen employed. To design the structure, the regulation ACI318-14, the 9th subject of national building regulations (DERCB, 2013) and buildings design regulations against earthquakestandard 2008 (ERDBR, 2014) have been used. Figure 1 shows total schematic of the mentioned building.

In the following, the standard structural details employed in the building skeleton have been analyzed. Observing these details have caused to the increase of ductility in the structure and its resistance against earthquake.

\section{Analyzing the Relation between Ductility and Energy Absorption Level}

In order that a structure can bear lateral loads with adequate confidence coefficient, two factors of adequate stiffness and appropriate ductility should be presented; particularly, when the imposed lateral load is alternative, for example, earthquake. The issue of ductility and input energy dissipation is very important. Absorbability and energy dissipation can be specified by investigating non-linear and inelastic behavior of structure. Their behavior is precisely implementing building details during construction.

Ductility is used as a criterion to provide reflection spectrums for strength design of structures against earthquake. Therefore, the minimum resistance required by a structure will be obtained based on inelastic design 
reflection spectrum. In 1956, for the first time, Heunser proposed an analysis of limit design based on energy. In his design, adequate energy absorption capacity of structure against large earthquakes is discussed as a confidence and health factor of structure. Based on Heusner's studies, an earthquake imposes energy to a structure a part of which is dissipated and another part of which remains as kinetic energy (mass movement) and strain energy (revocable deformation of structure members). Accordingly, using the following relation, the design can be related to the concept of plastic energy. In other word, $E_{p}=E_{t}-E_{e}$ where $E_{t}$ indicates the maximum kinetic energy of the structure that the structure shows against earthquake by assuming elastic behavior state. $E_{e}$ indicates the strain energy stored in yielding limit displacement. Although the above energy equation is a primary state, it has the primary principles of energy equation (Housner, 1956).

Due to certain problems in determining energy, their need and role in design processing, the energy related concepts were ignored for about 25 years. However, after the early 1990, the subject related to using energy concepts was highly considered and followed. Zahra \& Hall (1984) investigated parameters affecting seismic energy absorption in SDOF systems as well as the possibility of considering the number of equivalent plastic cycles as an important characteristic that are computed based on Hysteresis Energy (Zahrah \& Hall, 1984). Akiama (1985) studied limit state design of structures and attempted to explain the primary principles of energy method using the method proposed by Huesner. He also presented a method to design tall structures (Akiyama \& Hiroshi, 1985). Profoundly investigating energy parameters in balance equation, Yuan (1988) presented two types of energy balance equations with various mathematical definitions. Additionally, they revealed some deviating points in previously studies on input energy as well as Hysteresis Energy dissipation capacity computation. Bertro and Yuang can be considered as pioneers whose studies caused other researchers to conduct more analyses in this regard. They proposed that using input energy as a base for selecting design earthquakes can be useful. They also introduced input energy as a reliable parameter to define earthquakes; destruction potential (Tahooni, 2003). Wide parametric studies conducted by Fajfer, Vidik and Fishering about input energy and Hysteresis Energy spectrums and their ratio revealed the effect of various parameters on them. As a result of their study, new parameter of $\Upsilon$ was introduced that indicated the effect of low cycle fatigue phenomenon. They used these parameters to define equivalent ductility (Tahooni, 2001).

Simultaneous with introducing energy parameters, destruction indices computation for structures employed the accumulative advantages of these parameters. Makabe et al. proposed energy-based models. The second model is considered as one of the most popular destruction models to evaluate seismic destruction in concrete structures. Although the primary idea of destruction indices is seismic destruction evaluation after earthquake, the possibility of using destruction models to determine criteria for design was also discussed (Tahooni \& Ehtiyat, 2002).

Investigating the behavior of a certain substance is the first step for proper and precise analysis. If there is adequate information about materials' behavior employed in structure, the behavior of the structure can be estimated based on this information. To identify the behavior of structure, the best and the most reliable method is testing the behavior. As the most important and functional experiments to better identify structures' behavior is axial stretch and compression test through which ductility of concrete structures can be found.

To evaluate vulnerability of concrete structure, appropriate treatment of with earthquake phenomenon and accurate prediction of its effects on structure is highly important. Occurring destructive earthquakes during the recent decades as well as developing research methods and experimental facilities, it has been proved that the increase of structure strength as a single design parameter in traditional method cannot supply adequate safety by itself or decrease structural damage.

\section{Analyzing Energy and Its Relation with Hysteretic Energy}

Today, the concept of energy in structures is one of the parameters considered by researchers in their new approach to structures' behavior. Hysteretic energy that is wasted after yielding in hysteresis loops has very significant effect on creating structural damage. It is also regarded as one of the most important part of the equation of energy imposed on structures. Therefore, controlling this amount of energy can contribute to control structure's behavior and its damage level. The hysteretic energy amount in a structure can be an index of damage imposed or its softness level. To evaluate the vulnerability of structure, Park-Ang damage index can be used due to the effect of hysteretic energy. To this end, some structures have been designed with bracing and some others have been designed with shear wall. Also, their lateral loading has been selected ad designed according to regulations mentioned in the regulation of buildings design. The frame has been nonlinearized under three earthquakes simulated using dynamic analysis software and the level of damage imposed to each story has been computed. In the following, the diagrams of stories' relative distribution percentage and damage distribution in 
each story have been presented. With respect to damage distribution and hysteretic energy diagrams in stories, it can be concluded that the focus of damage and energy is on one or more stories. This fact leads to not exploiting the maximum system capacity. Therefore, single parameter resistance in seismic design is not enough and other parameter, namely hysteretic energy, should be used in structures' design.

Various studies revealed that destructive effects of earthquake are highly influenced by seismic energy received by structure during earthquake and it is not possible to completely predict these effects by non-linear resistance spectrum and even deformation. Followed by these researches, it was revealed that almost all parameters affecting seismic behavior of structures can be justified or applied in design process in the frame of energy concept. Therefore, desirable idea of energy balance in structure through damage distribution optimization is developing. One of the common methods of hysteretic energy computation in non-linear software is to compute the area under displacement-force curve which enters into inelastic area. This method involves investigating the behavior of entire system components in various response moments and should be performed during non-linear analysis. This method is very precise and used in non-linear analysis programs. Notably, Kanylmaz (2016) used a numerical model and compared its results with results at actual scale regarding hysteretic energy (Kanyilmaz, 2016).

In a numerical method called IDARC, to compute the damage, an index based on the pattern proposed by Park et al. (1984) was used. Park-Ang damage index for a structural element is defined as following:

$$
D I=\frac{\delta_{m}}{\delta_{u}}+\frac{\beta}{\delta_{u} \cdot P_{y}} \int d E
$$

Where $\delta_{m}$ denotes the maximum deformation due to earthquake load; $\delta_{u}$ is the durable final deformation for element; $P_{y}$ indicates yielding limit resistance; $\beta$ indicates yielding limit resistance, and $\int d E_{h}$ is the hysteresis energy absorbed by element during the response history (Young et al. 1987).

To decrease nominal resistance, Park et al. proposed $\beta=0.1$. Using this model, three damage indices are computed.

(1) Element damage index: Beams and columns

(2) Entire the story damage Story damage index: Horizontal and vertical components

(3) Entire the story damage

In other words, in this model, the level of accumulative damage in all members, stories and entire the structure is considered. To compute the damage in stories, the damage to beams and columns of each story as its members IDARC are firstly computed using software. Then, using weighting coefficients which are based on hysteresis energy dissipated in stories components and balance, the damages to the stories and entire the frame are computed. Therefore, it is necessary to precisely implement executive details of structure based of international standards and regulations. Hence, the present study investigates the process of proper implementation of executive details of beams and columns.

Column is regarded as one of the most important structural members which are designed at the first level to endure axial pressure. Almost all columns are influenced by bending moment. These moments can be due to rigid connection of beam to column, exiting from random centers through lack of proper positioning of axes or changes at cross-section level or materials' properties. In designing columns of this structure, in addition to considering architecture regulations, difficulty and executive issues have been also considered; such that by the adequate increase of columns' dimension, necessary space for positioning beams with appropriate distances even in line with their overlapped area has been supplied. On the other hand, the possibility of proper and principled concreting has become possible.

(1) The way of implementing columns can be stated in the following stages:

(2) Reinforcing column

(3) Framing column

(4) Concreting column

(5) Removing concrete frame

(6) Watering

In concrete columns and in designing based on ductility, stirrups should be necessarily considered with close distances and a series of other arrangements should be observed regarding putting rebar which practically 
increases behavior coefficient, leading to earthquake load reduction. It may seem that it is not accurate since ductility has nothing to do with exploitation time of structure; but, it is not really so. By compressing stirrups in columns, more loading capacity in columns is used and buckling in columns is delayed. Our computations in column resistance are firstly based on strains created in cross section and force balance. However, the column suffers buckling sooner and its capacity is decreased. In fact, compressing stirrups leads to the increase of the column's capacity.
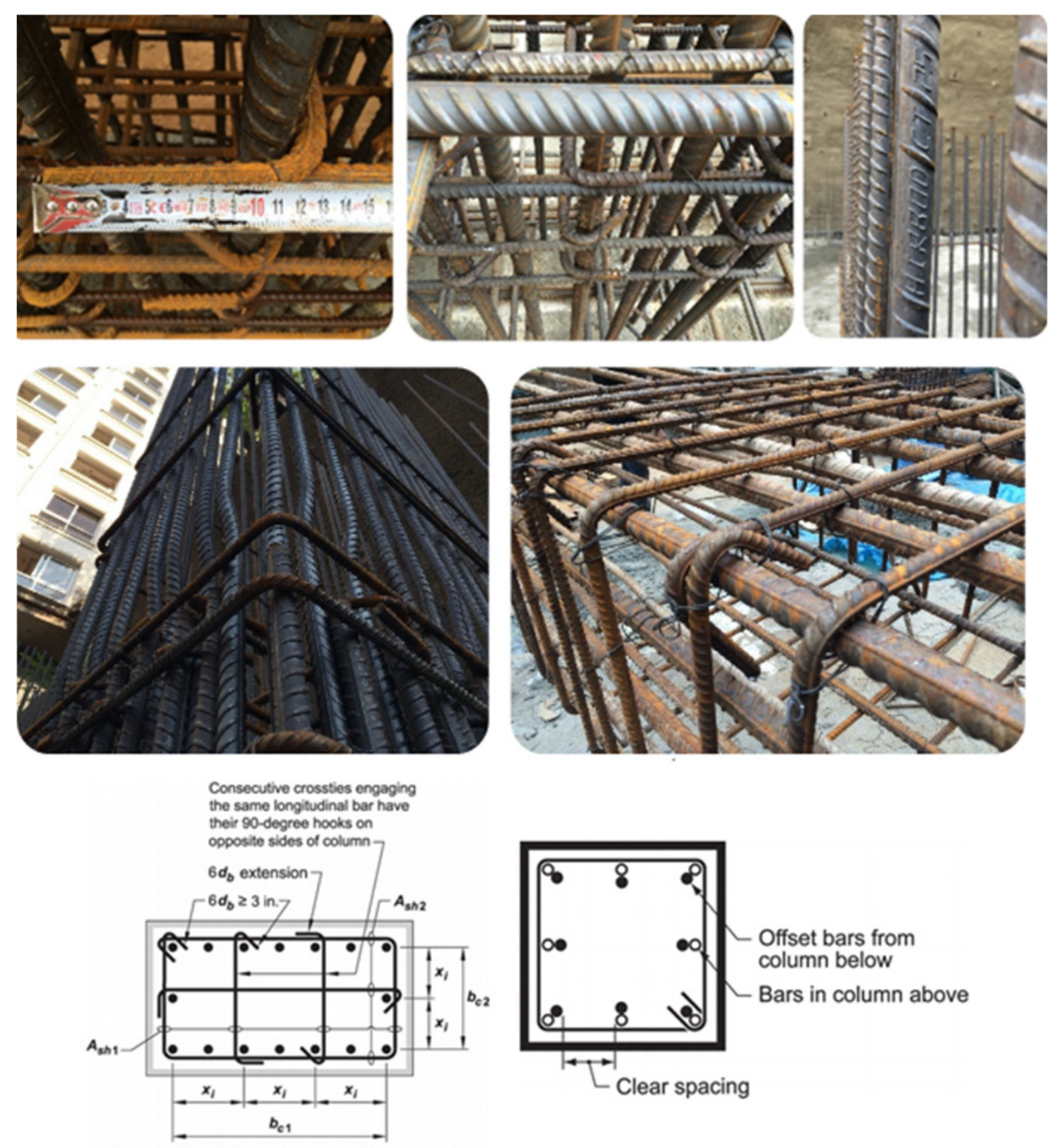

Figure 2. Example of transverse reinforcement in columns, Offset column bars
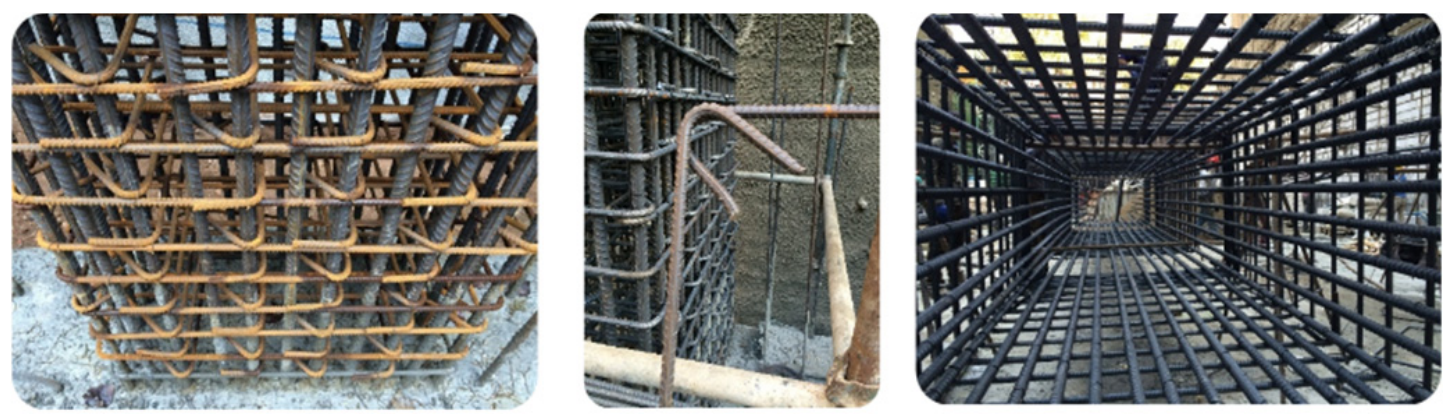

Figure 3. The end of are bent at 1350 , such do not open during strong earthquake shaking 
Beams are one of the main members in elements sets used in building structures. In fact, the main duty of beams is to endure stresses due to shear force and bending moment due to loads imposed on it and the weight of the beam. In designing structures, beams are usually designed based on existing bending moment and shear regulation is controlled in them. The main characteristics of beams include profile, length and substance of formation. In the following figures, it is shown that observing necessary standards according to international regulations guaranteeing ductility and invulnerability of the considered formation. Using cost analyses and sensitivity analyses, compound beams can be also employed (Eskandari \& Korouzhdeh 2016).
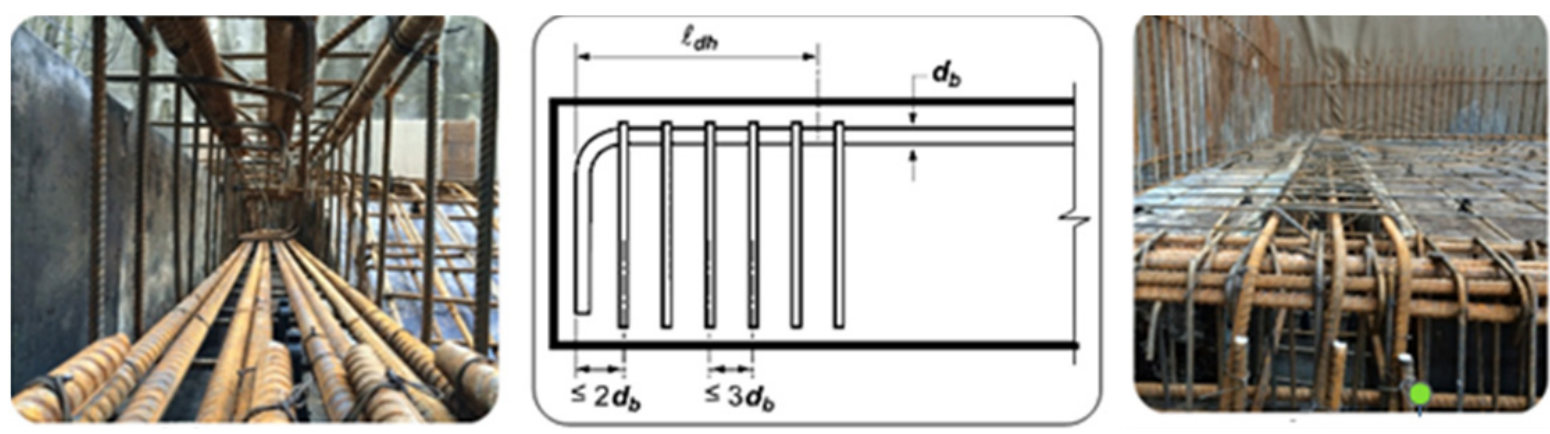

Figure 4. Ties or stirrups placed perpendicular to the bar being developed, spaced along the development length $\ell \mathrm{dh}$

When there is the possibility of bending yielding of cross section, it is forbidden to use reinforcements' covering patches. It is due to the fact that such patches are not reliable under alternative loading conditions in inelastic area. Due to losing shell concrete, it is necessary to put latitudinal reinforcements (closed stirrups or spiral reinforcements) for covering patches in each cross section (Murty, 2010).
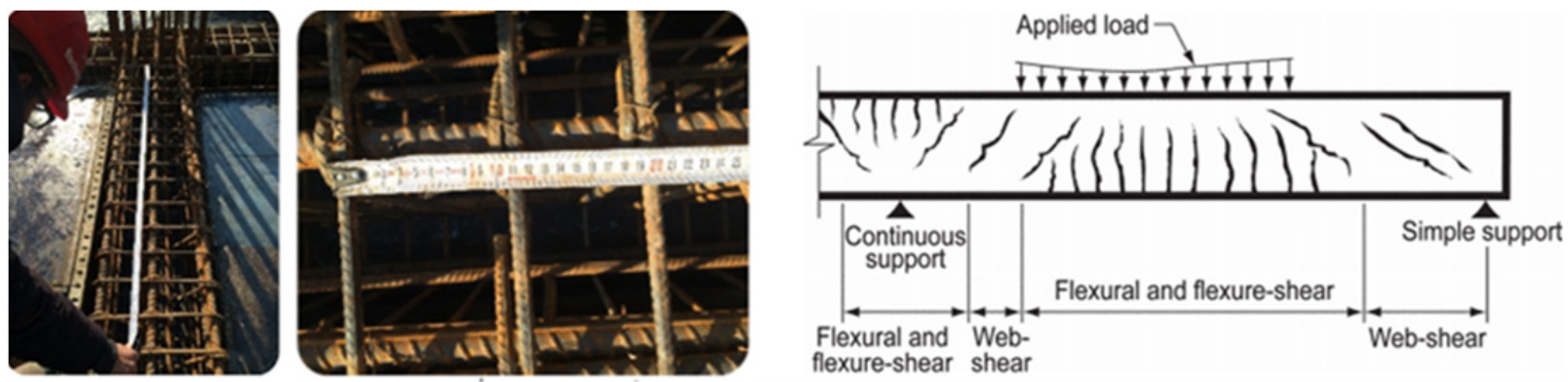

Figure 5. Types of cracking in concrete beams, Location and amount of vertical stirrups in beams 


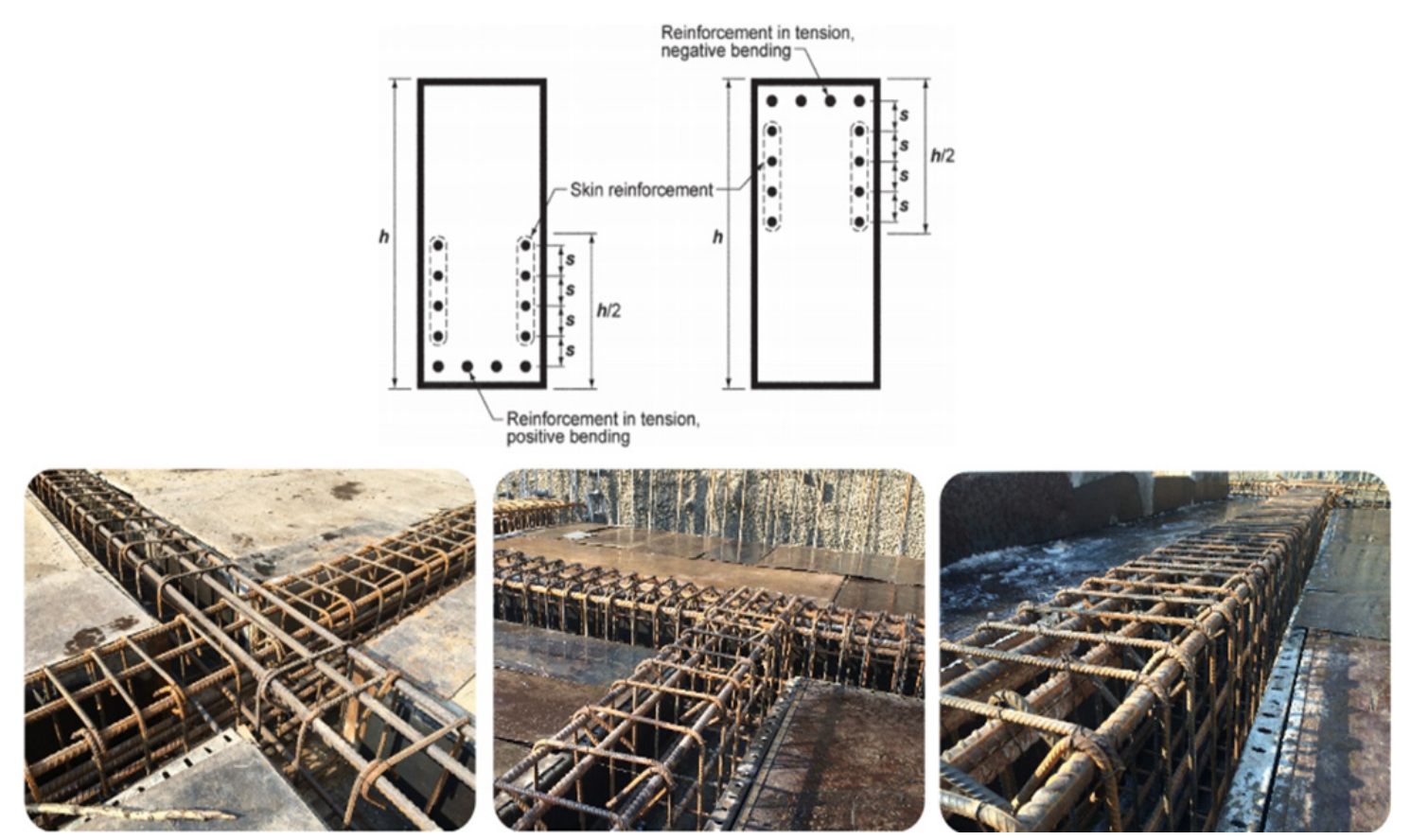

Figure 6. Various details of beams', Skin reinforcement for beams and joists with $\mathrm{h}>36$ in

In buildings whose strength element against lateral forces is bending frame, beam-column rigid connection is the main factor of structure as a bending frame. Investigating damages imposed to reinforced concrete frames due to earthquake indicate that most of damages imposed to such frames occur in beam-column connection area.

Under current conditions, most of regulations oblige to observe commands supplying resistance and ductility of beam-column connection area.
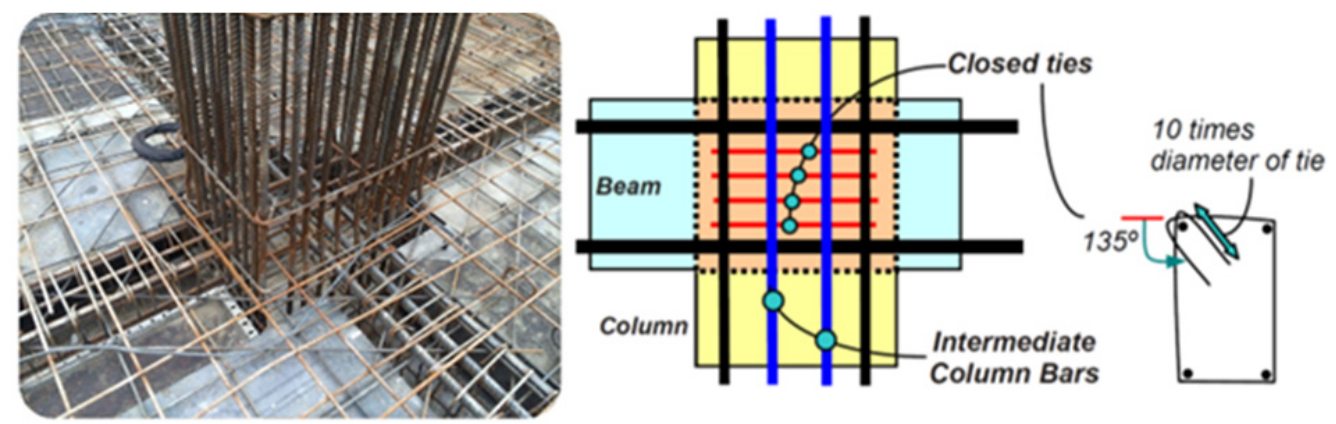

Closed loop steel ties in beam-column joints, such with $135^{\circ}$ hooks resist ill effects of distortion joints

Figure 7. Details of beams reinforcement in beam-column connection providing shear reinforcements (closed and pin stirrups) in beam-column connection area to increase shear resistance and connection ductility

Another part of a system affecting ductility and energy absorption of concrete structure is concrete floor slab. Usually, horizontal reinforced concrete slabs have a thickness of $10-50 \mathrm{~cm}$ and are mainly used in stories' floor. In most of residential and industrial buildings, during constructing ground story, building foundation is used as a bearing for thick concrete slabs. In tall buildings and skyscrapers, floor of each story is made by putting prefabricated concrete slabs with low thickness among steel frames. 

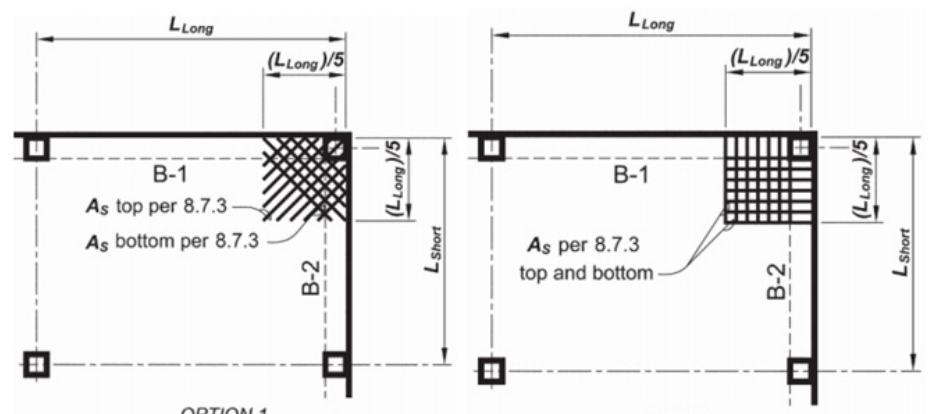

Notes:

OPTION 2

1. Applies where $\mathrm{B}-1$ or $\mathrm{B}-2$ has $\alpha_{f}>1.0$

2. Max. bar spacing $2 \boldsymbol{h}$, where $\boldsymbol{h}=$ slab thickness.
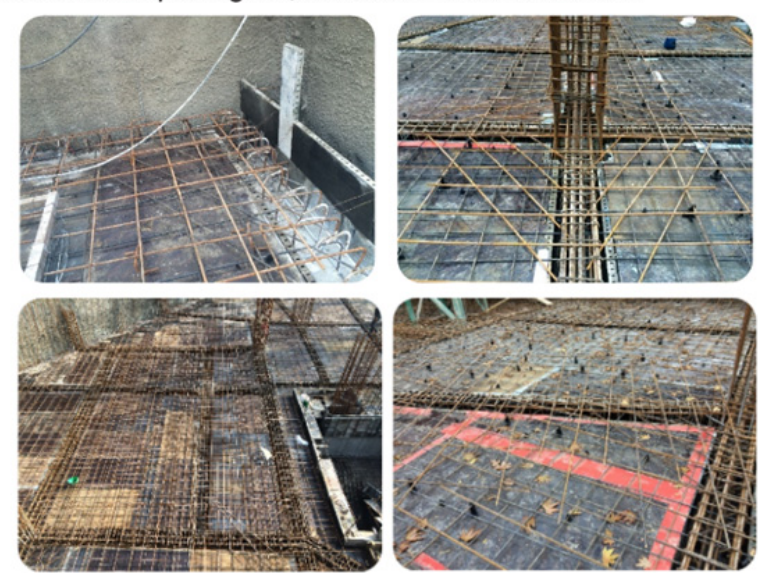

Figure 8. Details of slabs reinforcements, Slab corner reinforcement
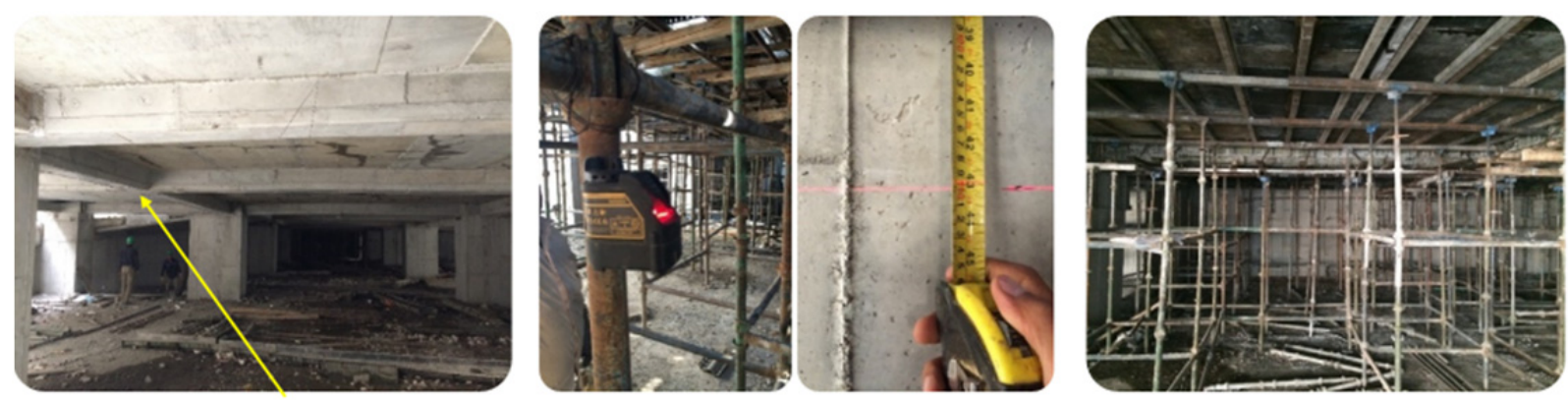

Figure 9. Applying pre-cracking deflection in slabs
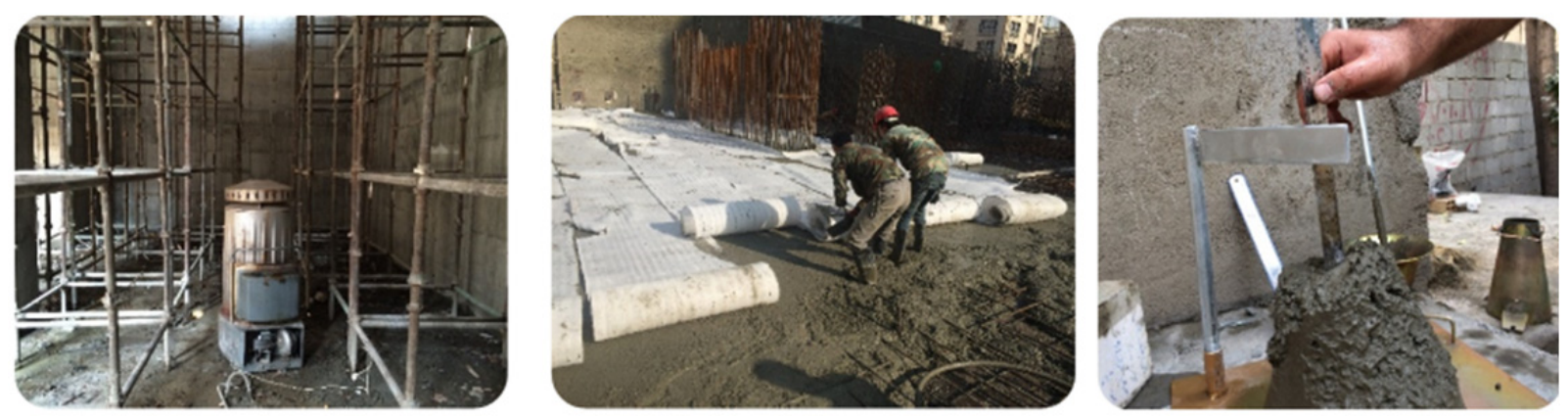

Figure 10. Other complementary efforts in slabs 

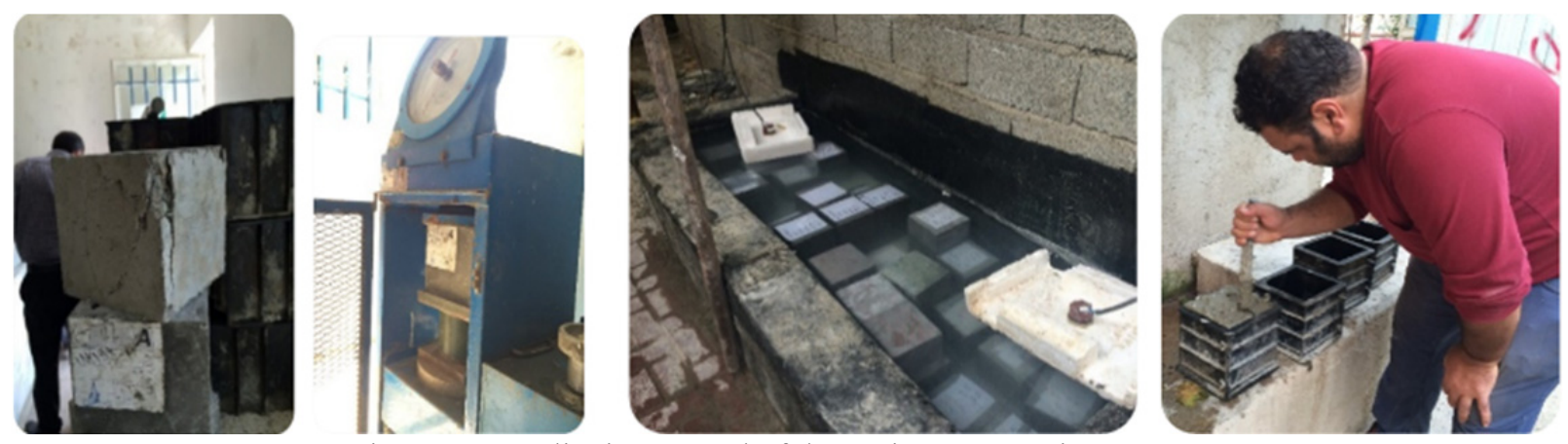

Figure 11. Qualitative control of the project's executive process

The research shows that most of structures in destructive earthquakes are entered into inelastic area. Hysteretic energy that is wasted after yielding in its hysteresis loops has a main effect on creating structural damage of the system such that it is the most important component of energy equation imposed on structures. Therefore, controlling this amount of energy can be led to controlling structure behavior and its damage level. The amount of hysteretic energy in a structure can be an index of imposed damage level or its softness level. However, this total value never indicates damage distribution in various structure elements (beam and column), behavioral structure shape and the type of formation as well as yielding work or its collapse.

To investigate the way of absorbing and energy waste as well as damage distribution in tall structures stories, hysteretic energy distribution diagrams, the maximum relative displacement, and damage distribution in structure stories in various earthquakes should be evaluated and implemented at the stage of precisely implementing structure based on the results of structure details. The research findings indicate that although the damage imposed to the structures is low, the damage distribution diagrams and hysteretic energy in stories indicate the focus on damage and energy in one or more stories. This fact causes lack of exploitation from the maximum system capacity.

\section{Analyzing the Effect of Loading System Type on Tall Structures Behavior}

Due to high lateral displacements and the creation of moments and large forces in structural members, lateral forces imposed on structures always play a critical role in analyzing and designing structures. The effect of lateral forces is more specified when the design of structures with high height or heavy loading is considered. In such structures, if designing is performed only based on elastic behavior, the design will not be affordable due to the creation of large dimensions of cross sections. Therefore, investigating inelastic behavior of structures is also highly important. Hence, examining the behavior of various systems resistant against lateral loads (elastic and inelastic) is one of the most important domains of structure engineering research. For instance, BIB is of primary systems to cope with lateral loads. In this frame, column-beam connection is fixed and when the frame is subjected to lateral load, due to moment transmission between beam and column, each of these two members show resistance against lateral load. In BIB, fix acts due to the stiffness of members to cope with moments resulted by lateral load and this stiffness is not so considerable, there is high lateral moment change in this system. Further, in these frames, due to very high moments crated at the end of column and beam, the dimensions of cross sections become very high and the design becomes unaffordable (Mahmoudi et al., 2016).

To make the resistant bending frame system more strength and rigid, the combination of BIB and knee element can be used. This system has more ductility and stability compared to bending frame; however, by increasing lateral force, the system will not have enough resistance as well.

Various methods are used to analyze compressive members and the simplest method is modal analysis in which the second side of governing differential equations or partial derivation is zero and does not provide us information about the behavior after buckling. This method only recognizes buckling modes. In this method, it is tried to find the maximum resistance value of an axial member without exiting from the axis and under direct pressure without precise displacement. In this method, an ideal axial member is considered and it is assumed that only displacement that can occur is in the direction of applied compressive load. Also, compressive load that acts on the member axis does not produce latitudinal displacement until buckling load is arrived. However, since an actual axial member has primary defects such as exiting primary axis and in such members, latitudinal displacement is started from the beginning of applying compressive axial force and there is no bifurcation point or sudden change in displacement during compressive load increase (Akiyama, 1985). Therefore, buckling 
resistance or maximum capacity of compressive load bearing for compressive members with the primary member defect should be determined by other methods such as finite element method. In these methods, compressive axial load behavior- shortening during total loading path till final load including low deflection or loading in compressive axial load curve- should be determined. Following the example of hysteretic curve is presented in Figure.

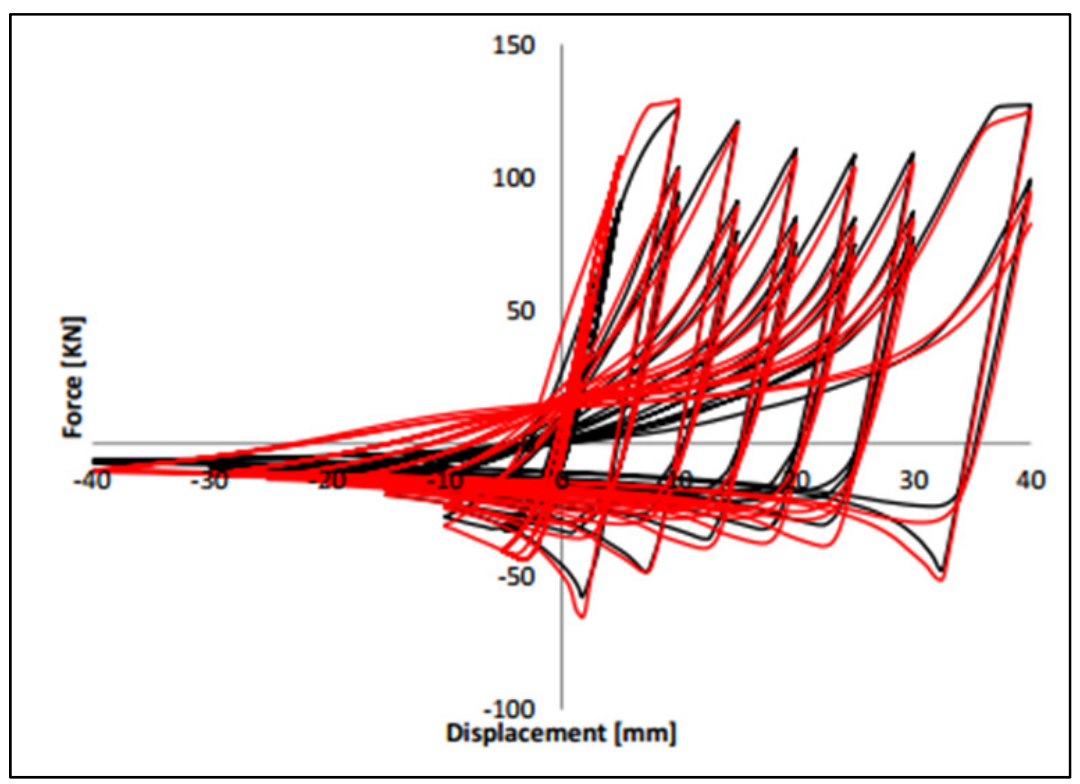

Figure 12. Hysteretic loop of the frame (Kanyilmaz, 2016)

\section{Analyzing the Relation between Ductility and Energy Absorption in Tall Structures Loading Systems}

Ductile materials refer to those substances that show high buckling during load bearing. For structures, ductility is the ability of undergoing considerable inelastic deformations before member destruction. A ductile member should be firstly able to adequately bear high inelastic deformations without decreasing its resistance. Secondly, ductile member should absorb and dissipate a considerable amount of earthquake energy through stable behavioral cycles. In steel buildings, in order than members can bear alternative loads due to earthquake in several cycles, they are designed such that members' behavior goes beyond elastic limit and deformations are created in the members. In this state, if members and connections can resist against these deformations, frame acts as alternative loads damper and a high amount of earthquake energy is absorbed.

In this study, shear walls behavior, bending frames and compound systems of bending systems and shear wall have been investigated. Analyzing bending frames and compound systems in tall structures inevitable requires dynamic analysis. Here, various non-linear behaviors of structure are discussed. Then, the structure analysis stages are explained. The causes of non-linear behavior of structure can be classified into three classes:

(1) State transformation: Some of non-linear behaviors depend on substance or structure state; for instance, a truss member that only bear tension or is in stretched and strength state or in loose state. A sliding support is eight her in contact state or in contact-free state.

(2) Geometrical non-linear behavior: If a factor causes a large deformation in structure, geometrical deformation of the structure can cause non-linear response. For instance, when a cantilever beam is bended under the load over it, this lateral load cause a deformation in cantilever such the beam stiffness is increased as a result of increasing load.

(3) Strain-stress non-linear relation: It is a general factor in non-linear behavior of substances. Many factors influence the behavior and characteristics of strain-stress of substance. These factors include the history of loading as elasto-plastic response form, environmental situations such as heat and loading duration. Various types of non-linear behavior are as following: Plasticity, Creep (deformation), Hyper-elasticity, Viscos-elasticity, and Inflation.

What is considered in analyzing the behavior of bending frames, shear wall and steel frames with truss members is non-linear behavior of substance (plasticity). Plasticity theory provides mathematical relation that specifies 
elasto-plastic response of substance. Plasticity theory includes three following parts:

(1) Yielding criterion: Determines the amount of stress in which yielding is started. For stress state, several components of yielding criterion is stated as a function of single components $F(\sigma)$. So, the mentioned function defined a single stress called equivalent stress:

$$
\sigma_{e}=F(\sigma)
$$

If equivalent stress is smaller than $\sigma_{y}$, substance is in elastic state and stresses will be expanded based on elastic substance's stress-strain relation. It should be noted that equivalent stress never can go beyond substance's yielding limit since in this state; plastic strains are expanded such that it leads to the decrease of yielding limit.

(2) Current law: This law determines the direction of plastic strains development and is stated as following:

$$
d \varepsilon_{p l}=\lambda \frac{\partial Q}{\partial \sigma}
$$

Where $d \varepsilon_{p l}$ specifies the increase of plastic strain; $\lambda$ indicates plastic coefficient specifying plastic strain level and $\mathrm{Q}$ is a function of stress that states plastic potential and specifies the direction of plastic strain. If $\mathrm{Q}$ is the same yielding function, current law is called unified and plastic strains occurs in vertical direction on yielding plate.

(1) Hardening law: This law indicates yielding plate change with yielding development such that situations are determined for next yielding limit. There are two accessible hardening laws: work hardening law and cinematic hardening law. In work hardening, yielding plate remains as much as previous amount around the primary central line and only its size is changed. In cinematic hardening, it is assumed that yielding plate size remains constant but yielding plate in stress space is transferred with yielding development.

Ductility means damage; that is, when ductility tool is used in designing to decrease forces due to earthquake, it is expected that damage is also exist after earthquake. An important subject in seismic design is ductility limits. Two ductility limits are defined as following:

(1) Existing ductility: this ductility pertains to structure and depends on configuration, materials characteristics, type of cross section type, gravity loads, stiffness decrease, resistance against reciprocating loads, etc.

(2) Required ductility: this ductility is resulted by earthquake effects and depends on earthquake magnitude parameters such as earth movement type, soil effect, natural period of structure against movement period, reciprocating cycle's number, etc.

If required ductility is less than existing ductility, structure cannot show appropriate deformation during earthquake without resistance reduction. Reciprocating loads can significantly affect structure and its member's behavior. Depicting load diagram against displacement when load is reciprocating is called hysteretic diagram. Using hysteretic diagram, the following items can be found:

(1) The surface curve of hysteresis diagram indicates the level of dissipated energy due to earthquake. The higher level indicates the higher ductility.

(2) Symmetry in hysteresis diagram indicates similarity of structure behavior in reciprocating loads. The higher symmetry in this diagram indicates the more even behavior of structure during earthquake.

(3) If slope diagram in subsequent cycles is decreased, the structure has stiffness degradation.

(4) If height diagram in subsequent cycles is decreased, the structure has resistance degradation.

(5) If height diagram in subsequent cycles is increased, the structure has hardening.

(6) If diagram does not pass an even path in a cycle, the structure has sliding.

(7) The number of diagram cycles indicates the structure's performance in earthquake.

To design modern systems, for an appropriate seismic resistant design, the hysteretic energy level wasted in main structure members should be minimized.

\section{Analyzing Compound System of Bending Frame and Shear Wall}

Special bending frame systems are not practical for buildings higher than 30 stories. In such cases, one of various types of shear wall is also used in the frame to make lateral loads strength. Shear walls are either concrete or lattice steel bracing (trussed). These walls may be internal cores such as cores around elevators and stairs or parallel walls insider building and/or vertical trusses. Various types of horizontal maps show different possible solutions for horizontal designs. Core systems in relation with building for are classified from the 
following points of view:

(1) External exponential cores

(2) Internal cores, exponential cores inside building

(3) Eccentric cores

The number of cores and the shape of cores used in compound systems (bending frame and shear wall) are presented as following: Single cores, Cracked cores, Multi cores, Closed shapes: Square, rectangular, circular, triangular, U shapes: I-shape and studs-shape, Building-inspired shapes

The present case study has been based on compound systems of bending frame and shear wall. To determine proper performance of structure, executing regulation in detail is highly important. Therefore, the method employed for shear wall is explained in the following. The important point in applying shear wall as lateral loader member is its arrangement in structure plan. Shear walls arrangement in the plan should be considered symmetric as much as possible to prevent torsion during earthquake.

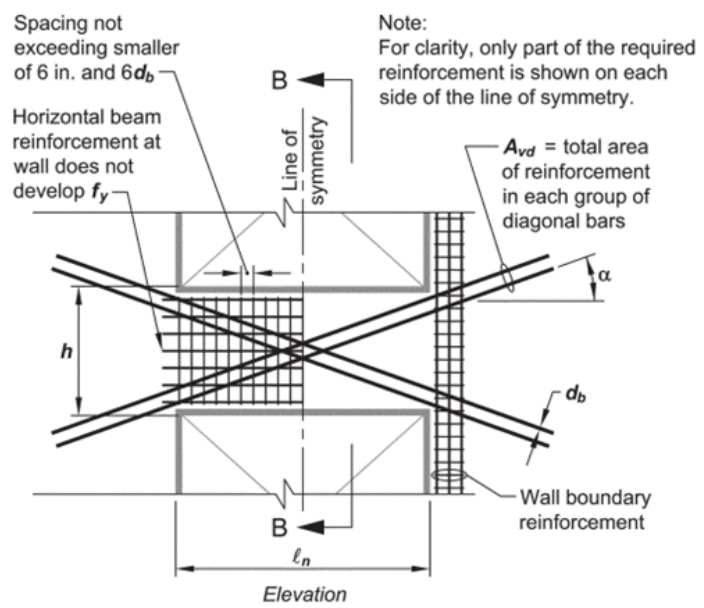

(b) Full confinement of diagonally reinforced concrete beam section

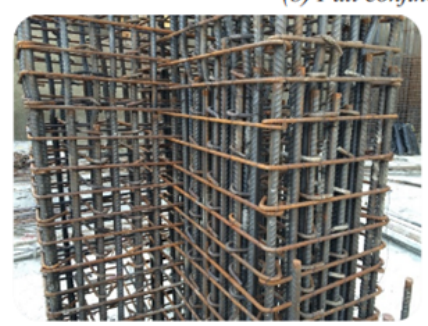

ransverse reinforcement

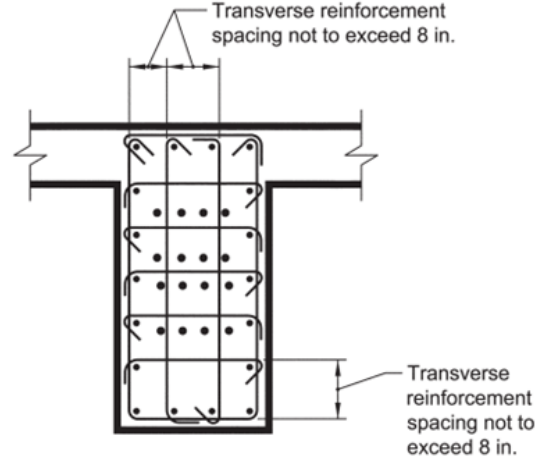

Section $B-B$

Note: Consecutive crossties engaging the same longitudinal bar have their 90-degree hooks on opposite sides of beam.

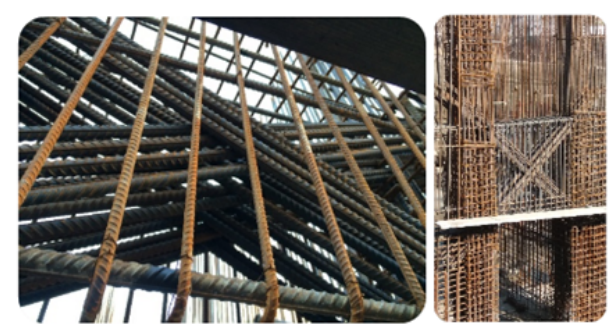

Figure 13. Coupling beams with diagonally oriented reinforcement, wall boundary reinforcement shown on one side only for clarity 

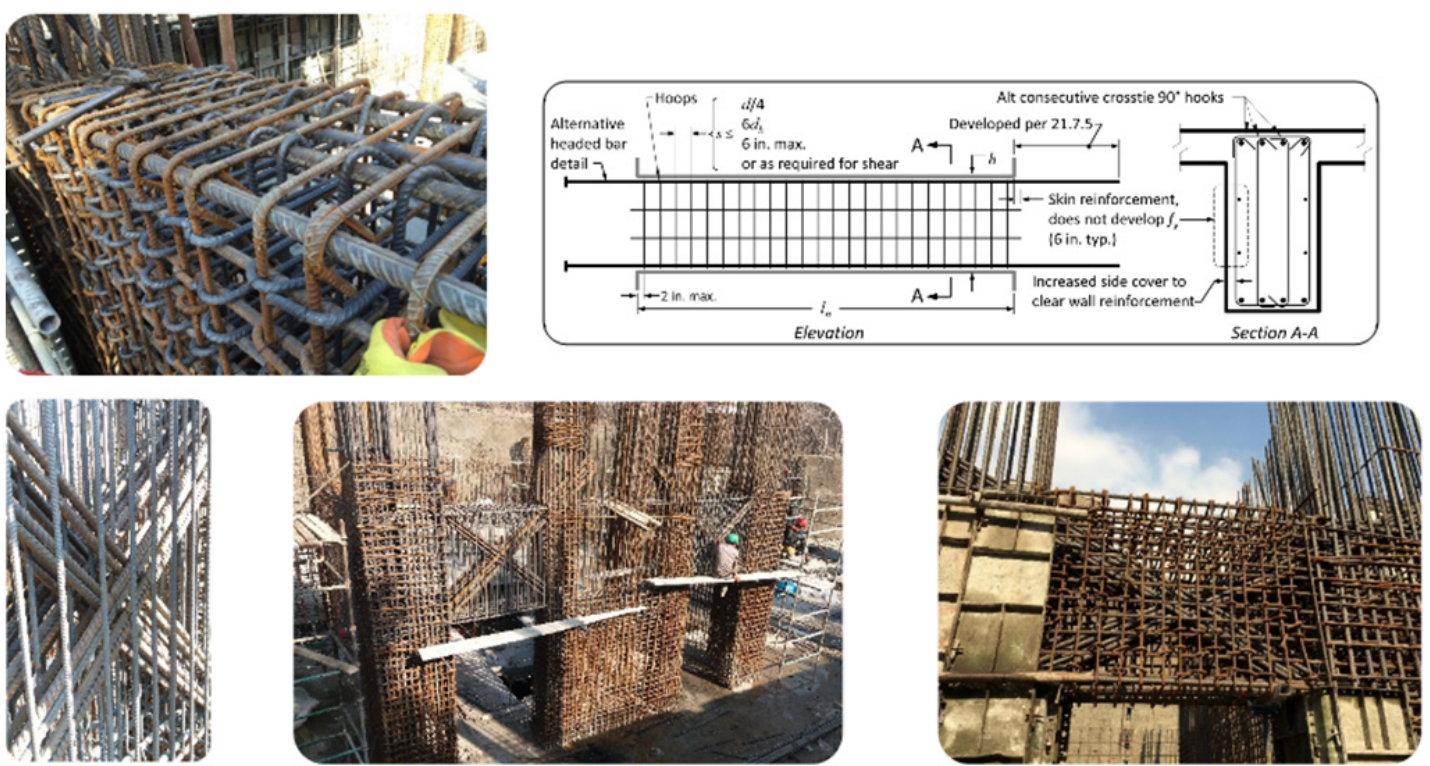

Figure 14. Various details of shear walls reinforcement

Latitudinal reinforcements are used to surround concrete and create a lateral support for barks in areas having the possibility of yielding. The lateral support has been defined as equal with a maximum angel of 135 degrees for each vertical bark. Since it is expected that concrete become shell shape during strong movements (especially near to bending yielded area), all reinforcements should be in the form of closed stirrup and have standard seismic hook.
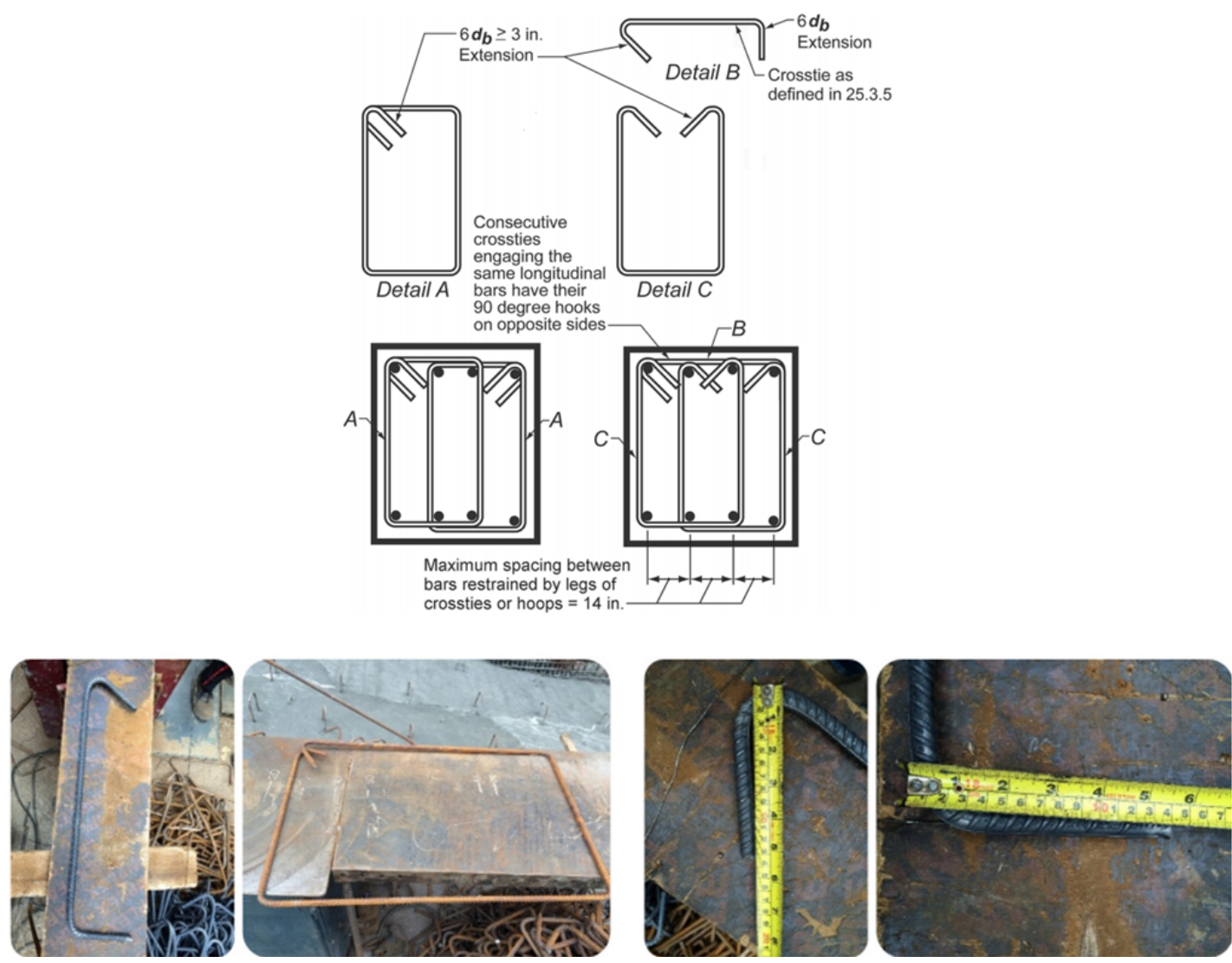

Figure 15. Examples of overlapping hoops and illustration of limit on maximum horizontal spacing of supported longitudinal bars 
In regulations, very complex and difficult details have been considered for coupling beam; however, as shown in figure, all details have been observed, indicating that all they are practical. Accordingly, as per following, compound systems are classified based on their behavior under lateral loading.

(1) Compound systems consisting of joint frame and shear wall: in this system, since frame beams re connected to column beams, frame only is able to bear weight loads. Shear wall resists against all lateral loads.

(2) Compound systems consisting of joint frame, Vierendeel frame and shear wall: lateral forces resist through shear wall and rigid frame (Vierendeel frame). Internal frames and longitudinal exponential frames only bear weight loads.

(3) Compound systems consisting of rigid frame and shear wall: merely employing shear walls to absorb lateral loads for heights above 500 foots is impractical. To have adequately strong cores, their dimensions should be selected very large. In this case, they are not appropriate for vertical transportation and energy distribution devices anymore.

Additionally, their deformation may be not so high to create crack in partitions and windows or even create undesirable mental reactions in building residents. Employing rigid frame that share shear wall for lateral loads resistance leads to the high increase of building's lateral rigidity. Deformation of entire the system consisting of shear wall and rigid frame with mutual effect on each other is obtained by summing up separate wall and frame deformation states.

(1) Rigid frame's cut state deformation: note that the slope of deformation curve in the bottom of building is maximized, where the highest shear is effective.

(2) Shear wall's bending state deformation: shear wall may be a center-filled concrete wall or a vertical steel truss. Shear wall acts as a vertical cantilever beam and is bent like it. Note that the slope of deformation curve in the top of building is maximized, where shear wall has the least proportion to create rigidity.

(3) Mutual effect of frame and shear core: to find mutual effect of frame and shear wall, two states' deformation states are summed up, resulting in a $\mathrm{S}$ curve. Due to various deformation characteristics of shear wall and frame, shear wall is forwarded in the top of building through the frame and is back warded in the bottom of building. Therefore, shear due to wind or earthquake in the top of building through the frame in the bottom of building is controlled through shear wall.

\section{Conclusion}

Based on the research findings, design regulations for ductile and earthquake-resistant reinforced concrete can be considered as following:

(1) Ductility and high energy loss capacity is supplied with low stiffness degradation.

(2) Beams should reach yielding state before columns.

(3) Bending discontinuity is prior to shear fracture.

(4) Connections should be stronger than members ending to them.

(5) Since beams are more ductile than columns, the sum of columns' moment capacities in the place of beam-column connection should be more than the sum of beams' moment resistance along each main plate.

(6) To increase shear resistance, compared to bending, shear steel should be provided as enough as possible. Also, to prevent continuity fractures, patches and bark bracing are adequate. As much as possible, creating patch in maximum stress points should be prevented. At the place of patch, it is appropriate to use stirrups and closed angles.

To ensure about ductility, designer engineer, during implementation, should consider disconnecting barks, patches and nodes' details. Fortunately, by considering few details which are simple and low cost, considerable ductility and safe structures against earthquake can be achieved. It should be noted in Nakhjavan Palace project implementation details in compliance with national and international regulations have been trying to achieve structurally safe and earthquake resistant.

\section{References}

ACI Committee 318. (2014). Building Code Requirements for Structural Concrete (ACI 318-14) and Commentary on Building Code Requirements for Structural Concrete (ACI 318R-14). American Concrete Institute, MI: Farmington Hills.

Akiyama, H. (1985). Earthquake-resistant limit-state design for buildings. University of Tokyo Pr. 
http://dx.doi.org/10.1002/eqe.4290140112

Earthquake Resistant Design of Buildings Regulations, 2800 (4th Ed.), (2014). Research center way, housing and urban development, second edition, February.

Eskandari, H., \& Korouzhdeh, T. (2016). Cost optimization and sensitivity analysis of composite beams. Civil Engineering Journal, 2(2), 52-62.

Housner, G. W. (1956). Limit design of structures to resist earthquakes. Proc. of 1st WCEE, 5-1.

Kanyilmaz, A. (2016). Validation of Fiber-Based Distributed Plasticity Approach for Steel Bracing Models. Civil Engineering Journal, 1(2), 1-13.

Mahmoudi, J., Mohammad, A., Arjomand, Masoud R., \& Mohammad, H. M. (2016). Predicting the earthquake magnitude using the multilayer perceptron neural network with two hidden layers. Civil Engineering Journal, 1, 1-12.

Minimum Design Loads for Building and Other Structures (ASCE/SEI 7-10); ASCE, Reston, VA, (2010).

Murty, C. V. R. (2010). Structural details in concrete. Indian Institue of Technology Kanpur and Building Material and Technology Promotion Council. India: New Delhi.

Park, Young, J., Andrei, M., Reinhorn, \& Sashi, K. K. (1987). IDARC: Inelastic damage analysis of reinforced concrete frame-shear-wall structures.

Tahooni, S. (2001). The design of reinforced concrete structures - volume II. Dehkhoda Press, spring.

Tahooni, S. (2003). The design of reinforced concrete structures - first volume. Dehkhoda Press, winter.

Tahooni, Shapur, Ehtiyat, \& Majid (2002). Load and Load-Bearing Structural Systems (SID). Amirkabir University of Technology, first edition, winter.

The Ninth Issue of National Building Regulations. (2013). Design and execution of reinforced concrete buildings. Iran's Development of Publishing, first edition.

Zahrah, T., \& Hall, W. (1984). Earthquake Energy Absorption in SDOF Structures. In: J. Struct, Eng., http://dx.doi.org/10.1061/ (ASCE) 0733-9445(1984)110:8(1757)

\section{Copyrights}

Copyright for this article is retained by the author(s), with first publication rights granted to the journal.

This is an open-access article distributed under the terms and conditions of the Creative Commons Attribution license (http://creativecommons.org/licenses/by/4.0/). 